\title{
Benchmark study on algae harvesting with backwashable submerged flat panel membranes
}

\author{
Tom De Baerdemaeker ${ }^{\mathrm{a}, *}$, Bert Lemmens ${ }^{\mathrm{a}}$, Chris Dotremont ${ }^{\mathrm{a}}$, Jorien Fret ${ }^{\mathrm{b}}$, Luc Roef ${ }^{\mathrm{b}}$, Koen Goiris ${ }^{\mathrm{c}}$, \\ Ludo Diels ${ }^{\mathrm{a}, \mathrm{d}}$
}

${ }^{a}$ Flemish Institute for Technological Research, VITO, Boeretang 200, 2400 Mol, Belgium

${ }^{\mathrm{b}}$ Proviron, G. Gilliotstraat 60, 2620 Hemiksem, Belgium

${ }^{\mathrm{c}}$ Kaho Sint Lieven, Gebroeders De Smetstraat 1, 9000 Gent, Belgium

d University of Antwerp, Department of Bioscience Engineering, Groenenborgerlaan 171, 2020 Antwerp, Belgium

\section{H I G H L I G H T S}

- Membrane performance on algae harvesting and water polishing was examined.

- Backwashable membranes were compared to a commercial non-backwashable membrane.

- Influences on critical flux for backwashable and benchmark membranes were examined.

- Backwashing showed significant advantage compared to relaxation.

- Membranes combined with centrifugation uses less energy than centrifugation alone.

\section{A R T I C L E I N F O}

\section{Article history:}

Received 26 June 2012

Received in revised form 25 October 2012

Accepted 29 October 2012

Available online 8 November 2012

\section{Keywords:}

Algae harvesting

Submerged membrane filtration

IPC

Water recycle

Polishing

\begin{abstract}
A B S T R A C T
The feasibility of algae harvesting with submerged flat panel membranes was investigated as preconcentration step prior to centrifugation. Polishing of the supernatant coming from the centrifuge was evaluated as well. The effect of membrane polymer (polyvinyl chloride [PVC], polyethersulfone polyvinyl-pyrollidone [PES-PVP], poly vinylidene fluoride [PVDF]), pore size (microfiltration [MF], ultrafiltration [UF]), algae cell concentrations and species were investigated at lab-scale. In addition, backwashing as fouling control was compared to standard relaxation. PVDF was the superior polymer, and UF showed better fouling resistance. Backwashing outperformed relaxation in fouling control. The backwashable membranes allowed up to 300\% higher fluxes compared to commercial flat panel benchmark (PVC) membranes. Estimations on energy consumption for membrane filtration followed by centrifugation revealed relatively low values of $0.169 \mathrm{~kW} \mathrm{~h} / \mathrm{kg}$ of dry weight of algae compared to $0.5 \mathrm{~kW} \mathrm{h/} / \mathrm{kg}$ for algae harvesting via classical centrifuge alone.
\end{abstract}

(c) 2012 Elsevier Ltd. All rights reserved.

\section{Introduction}

Microalgae represent a vast potential of high value chemicals, such as poly unsaturated fatty acids, carotenoids, and pigments. They are currently considered as a strong and emerging market for feed and food as well as for renewable chemicals production (Grima et al., 2003; Dragone et al., 2010; Wolkers et al., 2011; Mata

\footnotetext{
Abbreviations: CFM, critical flux measurement; CF, critical flux; CWP, clean water permeability $\left(1 / \mathrm{m}^{2} \mathrm{~h}\right.$ bar); DCW, dry cell weight of algae $(\mathrm{g} / \mathrm{l}) ; E_{\mathrm{W}}$, estimated energy consumption based on dry weight of harvested biomass $(\mathrm{kW} \mathrm{h} / \mathrm{kg}) ; E_{\mathrm{v}}$, Estimated energy consumption based on biomass volume $\left(\mathrm{kW} \mathrm{h} / \mathrm{m}^{3}\right)$; MTC, mass transfer coefficient or permeability $\left(1 / \mathrm{m}^{2} \mathrm{~h}\right.$ bar); PES-PVP, polyether sulfone polyvinylpyrrolidone; PVC, polyvinyl chloride; PVDF, polyvinylidene fluoride; TMP, trans-membrane pressure (bar); VCF, volume concentration factor.

* Corresponding author. Tel.: +32 143356 57; fax: +32 14321186

E-mail address: tom.debaerdemaeker@vito.be (T.D. Baerdemaeker).
}

et al., 2010; Becker, 2007; Singh and Gu, 2010). Since each species of microalgae contains different amounts of compounds, a careful selection of the algae species is necessary. After cultivation the microalgae have to be harvested in an intact state. Several harvesting techniques are already commercially available such as centrifugation, flocculation, flotation, coarse filtration and sedimentation (Borowitzka, 2005; Grima et al., 2003; Spolaore et al., 2006). A novel technique for microalgae harvesting is the use of membrane filtration (Rossignol et al., 1999; Greenwell et al., 2010; Ladner et al., 2010). Grima et al. (2003) reported cross-flow microfiltration (MF) and ultrafiltration (UF) as possible alternative techniques for microalgae harvesting. Membrane filtration was suitable to completely remove debris and microalgal cells from the culture medium. The removal of debris and bacterial loads is considered advantageous towards water recycling. Using tangential cross flow filtration for the recovery of microalgae over a membrane with pore size of 
$0.45 \mu \mathrm{m}$, Petrusevski et al. (1995) were able to recover large amounts of microalgae with an overall intact microalgal biomass recovery between $70 \%$ and $89 \%$. In the present study, submerged membrane filtration which is used in classical membrane bioreactors was evaluated as an alternative harvesting technique for microalgae (Xing and Wang, 2008). Bilad et al. (2012) have presented this option based on non-commercial membranes and a limited filtration setup. The Flemish Institute for Technological Research (VITO) has developed backwashable flat sheet membrane envelopes, based on the so-called integrated permeate channel (IPC) concept (Doyen et al., 2008).

An IPC (PES-PVP) membrane was compared to a commercial flat panel membrane to evaluate the ability of backwashing in microalgae filtration compared to relaxation for a standard commercial membrane. Additionally, different membrane materials and membrane pore sizes were tested for algae harvesting. Membrane performance was first evaluated on lab-scale. The critical flux was determined for the selected membranes for different operation modes (with and without backwashing) and for different microalgae species. These results were generated in preparation for longterm experiments at pilot scale.

Long-term filtration tests were performed on a single microalgae species with the most promising membrane prototype (i.e. the IPC UF membrane) and offset against the commercial flat panel PVC-MF membrane as a benchmark. Pilot tests were performed on algae suspensions as well as on the supernatant after centrifugation of the microalgae suspensions. The filtration behavior during long term tests should give an indication whether water polishing of the supernatant is technically feasible. Recycling of the polished water is essential for the sustainability of the algae production as the impact of salt inflow, water and nutrients can be reduced considerably (Pittman et al., 2010; Rodolfi et al., 2003; Uduman et al., 2010; Yang et al., 2011).

\section{Methods}

\subsection{Microalgal species}

Lab-scale membrane filtration tests were carried out using five different microalgal suspensions (Table 1). Fresh algae cultures were provided by Proviron and the KAHO St. Lieven College and were sampled at the end of their exponential phase (Table 1). Cell concentration was dependent on the process conditions during the cultivation cycle. Membrane filtration of the algae suspensions was started immediately after delivery to the lab. Prior to analysis the algae samples were stored at $4{ }^{\circ} \mathrm{C}$. The influence of cell concentration on the filtration characteristics was studied at lab scale at volumetric concentration factors (VCF) of 5,10 and 20. Pilot tests were performed with Nannochloropsis oculata in varying concentration dependent on growth conditions such as amount of nutrients and exposure to sunlight at the time of cultivation. A VCF is defined as the ratio of feed volume to retentate volume.

\subsection{Analytical techniques}

To determine dry cell weight concentration (DCW) of the algae suspensions, $100 \mathrm{ml}$ of algae sample was filtered over a $0.45-\mu \mathrm{m}$ fiber glass filter, followed by washing with $0.1 \mathrm{M}$ ammonium formate to remove salt from the algae suspensions. The algae paste was dried overnight at $105{ }^{\circ} \mathrm{C}$ to remove the remaining ammonium

Table 1

Microalgae species used in filtration tests.

\begin{tabular}{|c|c|c|c|c|}
\hline Algae species & Estimated size $(\mu \mathrm{m})$ & Type & Morphology & Picture $^{a}$ \\
\hline Nannochloropsis oculata & $1,5-3$ & Green; algae; flagellate & Spherical shape; rigid cell wall & \\
\hline Phaeodactylum tricornutum & $8-35$ & Brown; diatom & Oval, fusiform and triradiate; rigid cell wall & \\
\hline Isochrysis sp. & $3-5$ & Golden/brown; algae; flagellate & Spherical to pear shape; no rigid cell wall & \\
\hline Chlorella vulgaris & $2-10$ & Green algae & Spherical; rigid cell wall & \\
\hline Pavlova lutheri & $5-7$ & Golden/brown algae; flagellate & Spherical; no rigid cell wall & \\
\hline
\end{tabular}

a References: Algaelink, Wikipedia, Algaedepot. 
(a)
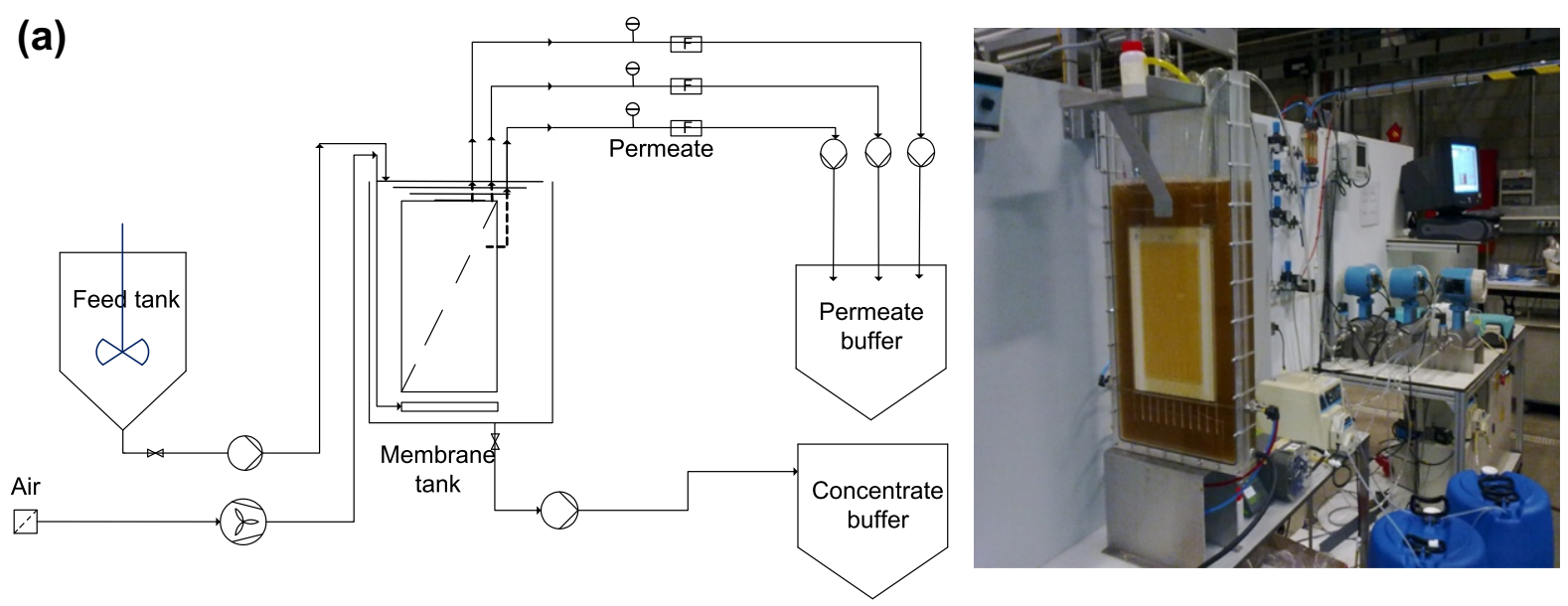

(b)
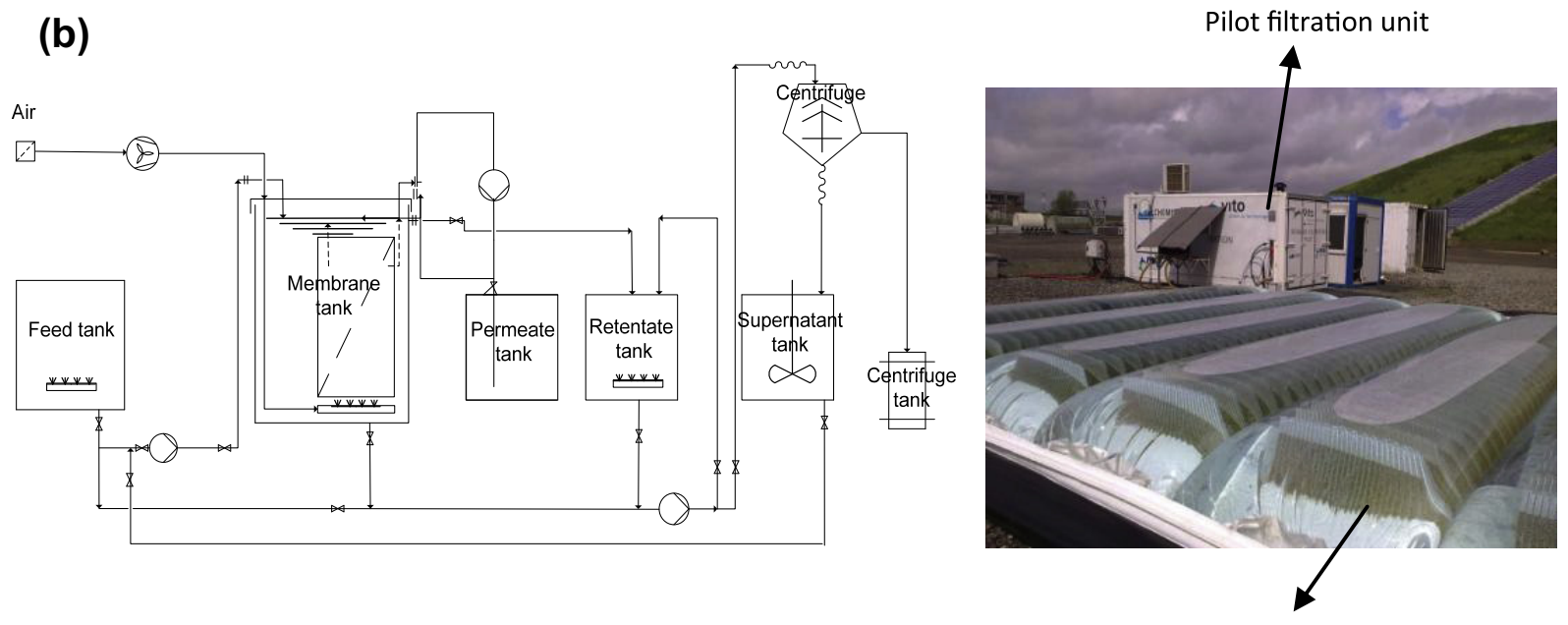

Algae production

Fig. 1. (a) Experimental set-up for lab scale microalgae filtration containing individual control for three membranes panels and (b) pilot scale set-up.

formate and water. The difference in weight between the filter containing the algae and the dry empty filter was the DCW concentration and is expressed as $\mathrm{g} / \mathrm{l}$ of dry weight of algae.

\subsection{Filtration equipment}

Both lab and pilot units were designed by VITO and monitored and controlled by a PC with proprietary steering software (MeFiAS $^{\circledR}$ ). In the lab unit, a maximum of three different flat panel membranes in different combinations can be simultaneously mounted in three parallel slots in the membrane tank and tested in batch operation mode. The filtration behavior of each individual membrane was monitored through pressure transmitters, flow transmitters and peristaltic pumps installed per individual membrane. The membranes were thus simultaneously immersed in the same algae suspension so that differences measured in membrane performance and fouling behavior can only be attributed to the membrane itself or its way of operation (with backwash or with relaxation), avoiding effects of variation in biomass.

Coarse bubble aeration was controlled per membrane such that the results of the immersed membranes were comparable. Membrane aeration was set to the equivalent value of $0.35 \mathrm{~m}^{3} / \mathrm{h} \mathrm{m}^{2}$ for a full scale single deck installation. Fig. 1 shows the experimental setup for lab scale and pilot scale filtration, respectively. The pilot-scale set up consisted of a separate membrane tank of $180 \mathrm{l}$, which can contain up to 11 full-scale flat panel membranes. The
Table 2

Specifications of membranes used in lab scale filtration tests.

\begin{tabular}{lllll}
\hline Membrane & $\begin{array}{l}\text { Pore size } \\
(\mu \mathrm{m})\end{array}$ & $\begin{array}{l}\text { Surface area } \\
\left(\mathrm{m}^{2}\right)\end{array}$ & $\begin{array}{l}\text { Backwash } \\
\text { possible }\end{array}$ & $\begin{array}{l}\text { Membrane } \\
\text { material }\end{array}$ \\
\hline IPC-MF & 0.1 & 0.079 & Yes & PES-PVP \\
IPC-UF & 0.05 & 0.079 & Yes & PES-PVP \\
PVC-MF (Benchmark) & 0.4 & 0.116 & No & PVC \\
Non-commercial MF & 0.4 & 0.116 & No & PVDF \\
\hline
\end{tabular}

membrane tank was connected to a feed, permeate, retentate and supernatant tank. The whole pilot unit was mounted in a container. The retentate tank was connected to a centrifuge for further concentration of the algae.

\subsection{Membranes}

A4 size membranes were used as listed in Table 2. The noncommercial backwashable IPC membranes were three dimensional fabric spacers, forming a membrane envelope. Fig. 2 shows the cross-section of a typical IPC envelope. The main advantage of the IPC concept is the ability to backwash the flat panel membranes up to a pressure of 2 bar. The effect of pore size on algae filtration was evaluated for MF and UF IPC membranes. To compare polymer performance, a non-commercial PVDF membrane was prepared. Physical cleaning of the submerged membranes was 


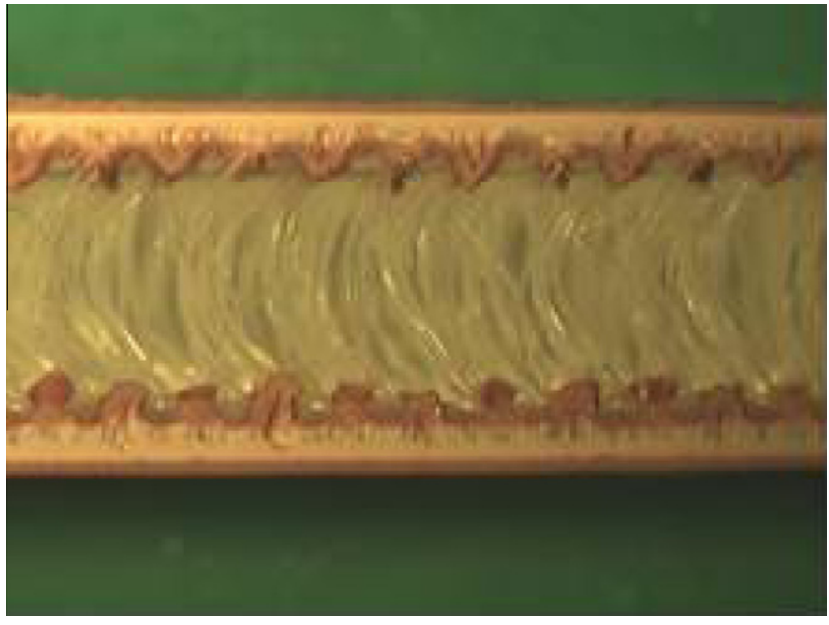

Fig. 2. Cross-section section of an integrated permeate channel (IPC) membrane.

achieved by relaxation or backwashing. Relaxation was achieved by ceasing the permeation while continuing to scour the membrane with air bubbles. Backwashing was achieved by reversing the permeate flow for a short period. The PVC-MF and PVDF-MF membrane cannot withstand backwashing and were operated in a filtration/relaxation regime. The effect of backwashing was evaluated on the IPC membranes by comparing filtration/relaxation and the normal filtration/backwashing regime. The aim of the pilot trials was to evaluate the best performing membrane against the benchmark PVC membrane at full-scale size with a single extraction module.

\subsection{Flux evaluation}

Critical flux measurements (CFMs) were performed in a stepwise manner, i.e. each step corresponds to a fixed flux for two consecutive cycles "filtration/relaxation" or "filtration/backwash". Fluxes were varied between 10 and $100 \mathrm{l} / \mathrm{m}^{2} \mathrm{~h}$, with steps of $10 \mathrm{l} / \mathrm{m}^{2} \mathrm{~h}$. Upon reaching either the maximum flux of $100 \mathrm{l} / \mathrm{m}^{2} \mathrm{~h}$ or the maximum allowable trans-membrane pressure (TMP), fluxes were decreased with steps of $10 \mathrm{l} / \mathrm{m}^{2} \mathrm{~h}$ to a minimum value of $10 \mathrm{l} / \mathrm{m}^{2} \mathrm{~h}$. The lowest flux value at which the second of the two consecutive filtration cycles showed an increasing TMP (or decreasing permeability or mass transfer coefficient, MTC) in comparison with the first cycle, was defined as critical flux (Bacchin et al., 2006).

\subsection{Energy consumption}

Energy consumption was calculated for a full scale installation ( $>100 \mathrm{~m}^{3} / \mathrm{h}$ influent) for one operational condition based on a flux of $28 \mathrm{l} / \mathrm{m}^{2} \mathrm{~h}$ for the IPC UF membrane and $10 \mathrm{l} / \mathrm{m}^{2} \mathrm{~h}$ for the PVC-MF membrane and compared to that of a centrifuge. For the calculation, the membrane modules were arranged in a single deck and typical assumptions for UF filtration were considered. The specific membrane aeration was fixed at $0.35 \mathrm{~N} \mathrm{~m}^{3} / \mathrm{h} \mathrm{m}^{2}$. The calculation took into account influent pumping, aeration, permeate pumping and concentrate pump. The energy consumption was calculated and expressed as $\mathrm{kWh} / \mathrm{kg}$ of dry weight of algae harvested and as $\mathrm{kWh} / \mathrm{m}^{3}$ of input flow of algae suspension. The data for the centrifuge used originated from the main supplier.

\section{Results and discussion}

\subsection{Lab-scale tests}

The critical flux measurement (CFM) is used as a tool to determine the membrane dirt load capacity in a short-term experiment, allowing for each membrane and for a given microalgae concentration and species to select a proper flux at which no irreversible fouling is expected to occur (Bacchin et al., 2006). However, it is important to emphasize that the CFM only gives partial information, as it only reveals short-term effects. Long-term effects were not measured on lab scale.

\subsubsection{Influence of membrane material}

The influence of the membrane material was tested by the filtration of $N$. oculata at an initial concentration of $1.49 \mathrm{~g} / \mathrm{l}$ (Table 3 ). The comparison was limited to MF-type membranes, i.e. the benchmark PVC, the IPC and a non-commercial membrane (PVDF). Each membrane was tested under identical filtration parameters: 4 min of filtration followed by 1 min of relaxation (no backwashing). Prior to the CFM, the clean water permeability (CWP) or clean water mass transfer coefficient (CWMTC) was determined for the different membranes with tap water. The clean water and CFM results are summarized in Table 3. The benchmark PVC membrane and the PVDF membrane showed a critical flux value of $50 \mathrm{l}$ / $\mathrm{h} \mathrm{m}^{2}$, whereas the IPC-MF membrane showed a critical flux of $40-50 \mathrm{l} / \mathrm{h} \mathrm{m}^{2}$ under an identical filtration regime. At the end of the CFM, the PVDF membrane retained the highest permeability (1800 l/h $\mathrm{m}^{2}$ bar, 28\% loss). The PVC and PES-PVP showed the same permeability ( $1000 \mathrm{l} / \mathrm{h} \mathrm{m}^{2}$ bar); however, the PVC lost most of the initial permeability during the test. After rinsing the membranes with water, the CWP was determined again. The PVC and PVDF membrane showed partial recovery of the MTC, indicating a reversible fouling layer on the membrane. The IPC membrane did not recover which is an indication of strong irreversible fouling, probably due to the operation of filtration and relaxation of a membrane specifically designed for use with backwashing. Operation of an IPC membrane under a regime it is not designed for also explains the low CF compared to that of the PVC or PVDF membranes. One can conclude that PVDF was the best polymer for this filtration.

\subsubsection{Influence of filtration regime and pore size}

The IPC concept is designed for filtration/backwashing regimes which is expected to result in a more stable filtration performance. Due to relaxation and backwashing, the net flux was lower than the gross flux during filtration. To allow easy evaluation of both systems, filtration conditions were chosen for a net flux of $80 \%$ of gross flux. The IPC UF type of membrane was submerged in a $N$. oculata suspension at high concentration $(8 \mathrm{~g} / \mathrm{l})$ to simulate severe fouling conditions at a fixed aeration of $200 \mathrm{l} / \mathrm{h}$ (equivalent of $0.35 \mathrm{~m}^{3} / \mathrm{m}^{2}$ for a single-deck full-scale installation). The high concentration was achieved by filtration through the same submerged membrane at moderate flux to avoid irreversible fouling. The $\mathrm{CF}$ was determined under varying filtration/backwash regimes as summarized in Table 4 . The results in Table 4 indicate that backwashing had a significant advantage over relaxation at identical recoveries, resulting in increased critical fluxes. Moreover, shorter filtration cycles reduced the impact of fouling on the membrane. A backwashing period of $5 \mathrm{~s}$ was not sufficient to control membrane fouling (results not shown); a backwash period of a minimum of $10 \mathrm{~s}$ appears to be necessary to overcome the effect of the expansion of the membrane envelope during backwashing. At normal filtration operation, the suction of the permeate extraction pump keeps both sides of the membrane surface tightened to the spacer 
Table 3

Impact of membrane material on critical flux measurements (in filtration/relaxation regime) with a Nannochloropsis oculata suspension of $1.49 \mathrm{~g} / \mathrm{l}$.

\begin{tabular}{|c|c|c|c|c|c|}
\hline Membrane & $\begin{array}{l}\text { CWP start } \\
\left(1 / \mathrm{m}^{2} \mathrm{~h} \text { bar }\right)\end{array}$ & $\begin{array}{l}\text { Critical flux } \\
\left(1 / \mathrm{m}^{2} \mathrm{~h}\right)\end{array}$ & $\begin{array}{l}\text { CWMTC at end } \\
\text { of CFM }\left(1\left(\mathrm{~m}^{2} \mathrm{~h} \text { bar }\right)\right.\end{array}$ & $\begin{array}{l}\text { MTC loss start } \\
\text { vs. end (\%) }\end{array}$ & $\begin{array}{l}\text { CWP after rinsing } \\
\text { membrane with } \\
\text { water }\left(1 / \mathrm{m}^{2} \mathrm{~h} \text { bar }\right)\end{array}$ \\
\hline PES-PVP MF (IPC) & 2000 & $40-50$ & 1000 & 50 & 1000 \\
\hline PVC-MF (Benchmark) & 2800 & 50 & 1000 & 64 & 1500 \\
\hline PVDF-MF & 2500 & 50 & 1800 & 28 & 2100 \\
\hline
\end{tabular}

Table 4

Impact of different filtration regimes on critical flux measurement (CFM) for an UF integrated permeate channel (IPC) membrane in a Nannochloropsis oculata suspension with backwashing at $150 \%$ of gross flux.

\begin{tabular}{lllll}
\hline $\begin{array}{l}\text { Algae } \\
\text { concentration } \\
(\mathrm{DCW})(\mathrm{g} / \mathrm{l})\end{array}$ & Operational parameters & $\begin{array}{l}\text { Critical } \\
\text { flux } \\
\left(\mathrm{l} / \mathrm{m}^{2} \mathrm{~h}\right)\end{array}$ \\
\cline { 2 - 4 } & $\begin{array}{l}\text { Filtration } \\
(\mathrm{min})\end{array}$ & $\begin{array}{l}\text { Backwash at 150\% } \\
\text { of filtration flux }(\mathrm{s})\end{array}$ & $\begin{array}{l}\text { Relaxation } \\
(\mathrm{min})\end{array}$ & \\
\hline 8.86 & 8 & 0 & 2 & 10 \\
8 & 4 & 0 & 1 & $10-20$ \\
8.86 & 8 & 40 & 0 & $10-20$ \\
8.4 & 4 & 20 & 0 & 20 \\
7.93 & 2 & 10 & 0 & $20-30$ \\
\hline
\end{tabular}

fabric, whereas during backwashing, permeate is sent back through the membrane through the integrated permeate channel, pushing both membrane sides away from each other and leading to an expansion of the membrane envelope. Therefore, a net flux increase of $150 \%$ can be expected for regimes with backwash compared to the typical flux values for standard filtration/relaxation operations. This result is confirmed by longer term filtration with Phaeodactylum. The IPC membranes performed better than the benchmark PVC-MF and the UF IPC (Fig. 3). This figure also shows that the IPC-UF membrane performed better than the IPC-MF, indicating the importance of pore size. These findings were confirmed in additional tests (Fig. 4a and b).

\subsubsection{Influence of microalgae species and concentration}

In a first trial, the critical flux was determined for different microalgal suspensions (Table 5) with the IPC UF membrane. Although the first three micro algal suspensions had similar algae suspension concentrations, the CF values were, contrary to expectations, not similar. For Chlorella and Phaeodactylum, which have a rigid cell wall on top of their cell membrane, the critical fluxes were twice as high compared to the critical flux for Isochrysis. The results for Nannochloropsis and Pavlova confirmed the importance of a rigid cell wall. Although the concentration of the Nannochloropsis was higher than that of Pavlova, the CFMs was equal. In a different test, the effect of cell concentration on filtration characteristics was evaluated for Nannochloropsis and Phaeodactylum suspensions by performing CFM at different VCFs (Fig. 4a and b). The figures show the measured CF in function of the DCW. Comparison between the two membrane filtrations leads to the conclusion that the decrease in CF was more severe for Nannochloropsis than for Phaeodactylum. The main differences in permeabilities, critical flux values and fouling dependency specific for each algae species can be explained by evaluating basic morphology and cell concentration (Arad et al., 1980; Doucha and Lívanský, 2008; Lewin et al., 1958). The cell membrane of Chlorella, Nannochloropsis and Phaeodactylum is surrounded by a rigid cell wall. A hypothesis is that this rigid multilayered structure reduces compressibility of the cell and allows for a packing without blocking water passage, much like marbles stacked together. The rigid cell wall is in great contrast with the morphology of Isochrysis or Pavlova which lacks a rigid cell wall (Table 4) and deform more easily, preventing water to pass between the cells towards the membrane surface. Also, Bilad et al. (2012) found that clustering of algae in the suspensions can promote biofilm formation which can result in extracellular polymeric substances (EPS) depositions on the membrane surface and in permeability loss due to pore blocking by the EPS. These combined

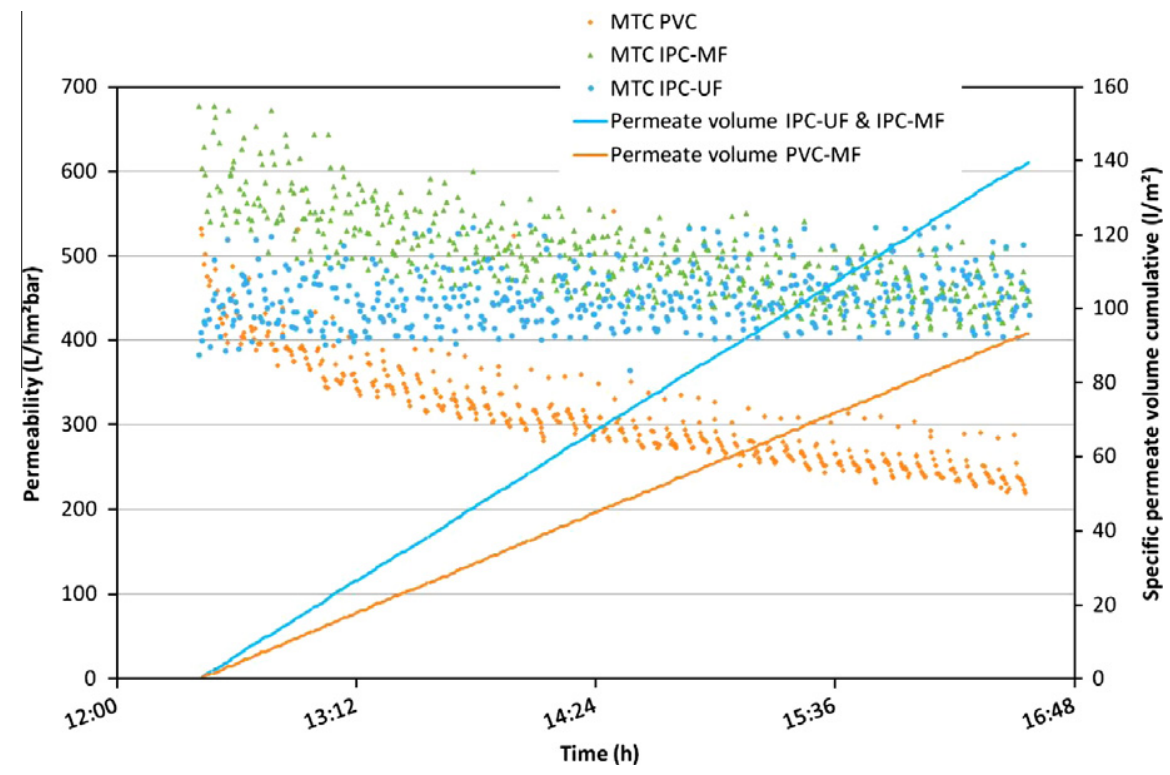

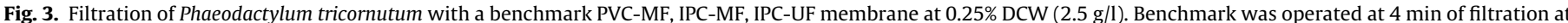

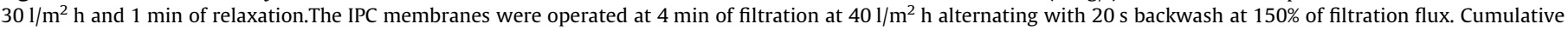
specific permeate volumes expressed as 1 per $\mathrm{m}^{2}$ membrane surface are shown on the second $Y$-axis. 
effects contribute to the reduction in filtration capability and result in lower CFM values (Babel and Takizawa, 2010; Zhang et al., 2008). For Phaeodactylum, the three different shapes present (oval, fusiform and triradiate cells) do not allow for high packing densities, facilitating the flow of water from to the surface of the membrane, leading to a higher CF and permeability (Lewin et al., 1958).

\subsection{Pilot scale tests}

Two fields of application in the harvesting of algae were identified in which membranes can play an important role to make the overall process more sustainable and economical: pre-concentration of algae prior to the final concentration step with centrifuges, and polishing of the supernatant coming from the centrifuge to allow recovery of water, salt and nutrients. Two membranes were evaluated during the pilot tests: the commercial PVC-MF as benchmark membrane and the IPC UF membrane. One of the main features of the IPC membranes is their suitability for backwashing, therefore the pilot tests with these membranes were mainly focused on the evaluation of the effects and further optimization of the backwashing procedure.

\subsubsection{Pre-concentration of algae}

One of the goals of the pre-concentration step is to achieve a large volumetric concentration factor with membrane filtration. Reducing the volume will have a significant impact on the investment cost of the centrifuge by decreasing its capacity requirements. Based on the results obtained at lab scale, the process parameters for the commercial PVC-MF membrane were fixed at a gross flux of $20 \mathrm{l} / \mathrm{m}^{2} \mathrm{~h}$ at a recovery of $80 \%$ for a Nannochloropsis
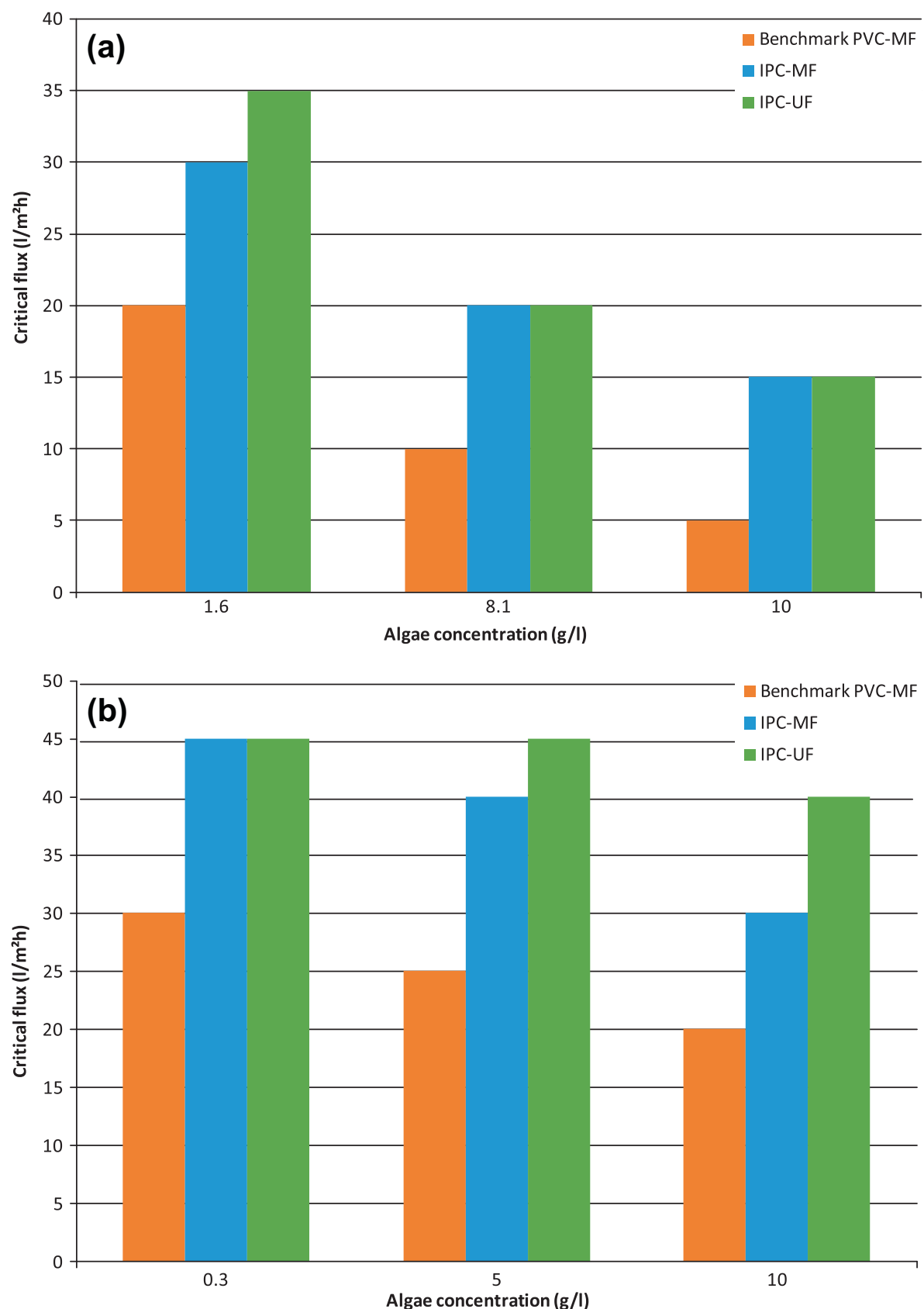

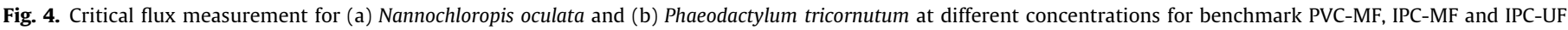
membranes. 
Table 5

Critical flux measurement (filtration/backwash regime) for different micro algae species for the UF integrated permeate channel membrane.

\begin{tabular}{|c|c|c|c|}
\hline Algae species & Concentration $(\mathrm{g} / \mathrm{l})$ & Critical flux $\left(1 / \mathrm{m}^{2} \mathrm{~h}\right)$ & Morphology (Table 1) \\
\hline Isochrysis & 0.3 & 15 & Spherical, no cell wall \\
\hline Chlorella vulgaris & 0.4 & 50 & Spherical, rigid cell wall \\
\hline Phaeodactylum tricornutum & 0.3 & 50 & Oval, fusiform, triardate, rigid cell wall \\
\hline Pavlova lutheri & 0.9 & 20 & Spherical, no cell wall \\
\hline Nannochloropsis oculata & 8.4 & 20 & Spherical, rigid cell wall \\
\hline
\end{tabular}

suspension of $2 \mathrm{~g} / \mathrm{l}$ DCW which corresponds to a VCF of 2 . The benchmark membrane was operated at successive cycles of 4 min of filtration alternating with $1 \mathrm{~min}$ of relaxation. As shown in Fig. 5a, during filtration at a flux of $20 \mathrm{l} / \mathrm{m}^{2} \mathrm{~h}$, a strong permeability decrease was observed as a function of time. Considering the magnitude of this decrease, a chemical cleaning of the membrane would be necessary after only two days of filtration. To regain stable filtration, the gross flux was decreased to a value of $10 \mathrm{l} / \mathrm{m}^{2} \mathrm{~h}$ without chemical cleaning. Stable filtration behavior is defined as a complete recovery of the initial process permeability after relaxation or backwashing for a period of at least $24 \mathrm{~h}$. Filtration tests were repeated with the IPC-UF membrane at a Nannochloropsis concentration of $3 \mathrm{~g} / \mathrm{l}$ DCW. On the basis of the previous lab-scale tests, the window of operation for having a stable process was expected to be larger for the IPC-UF membrane than for the PVC-MF membrane. The results shown in Fig. 5b indicate a stable filtration behavior and no decline in permeability, even for gross fluxes varying between 15,20 or $28 \mathrm{l} / \mathrm{m}^{2} \mathrm{~h}$. This result is in contrast with the filtration trial with the PVC-MF membrane in which a stable operation was obtained for fluxes as low
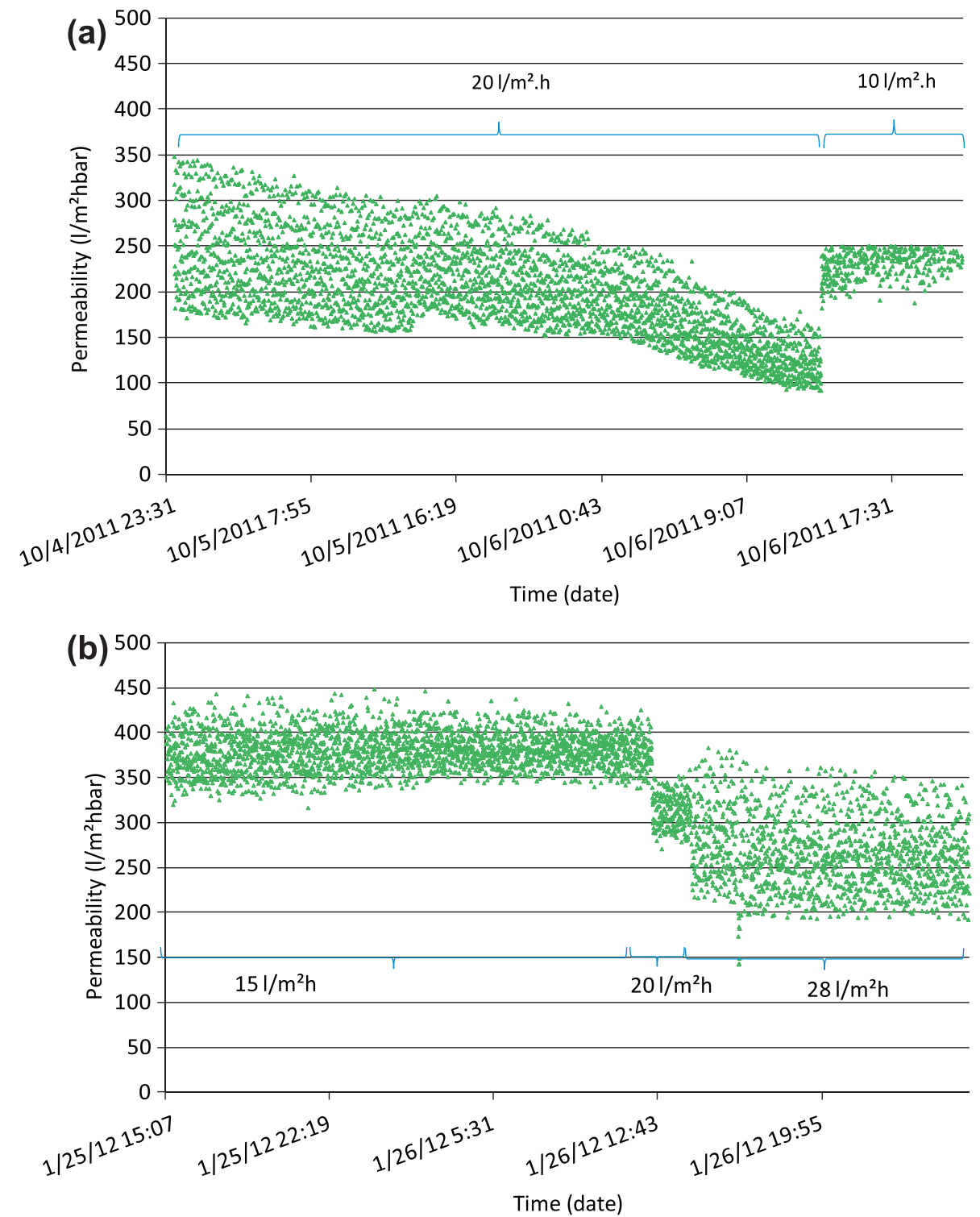

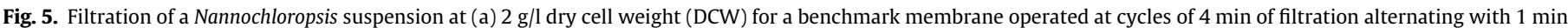
of relaxation and (b) at $3 \mathrm{~g} / \mathrm{l} \mathrm{DCW}$ for an IPC-UF membrane at cycles of 4 min of filtration at 15 or $28 \mathrm{l} / \mathrm{m}^{2} \mathrm{~h}$ alternating with $20 \mathrm{~s}$ backwashing at $150 \%$ of filtration flux. 
as $10 \mathrm{l} / \mathrm{m}^{2} \mathrm{~h}$, even at lower algae concentrations. Process flux of the IPC-UF membrane was about $300 \%$ higher compared to the flux of the benchmark membrane. Interestingly, the permeability of the IPC-UF membrane at a fixed flux of $28 \mathrm{l} / \mathrm{m}^{2} \mathrm{~h}$ was even higher than the permeability of the benchmark at fluxes of $10 \mathrm{l} / \mathrm{m}^{2} \mathrm{~h}$. This result proves that the IPC membrane has a clear advantage over the benchmark membrane in the pre-concentration step of algae during harvesting.

\subsubsection{Polishing of the supernatant}

Harvesting leads to large amounts of permeate and supernatant that need to be discharged. Recovery of water and nutrients during algae harvesting would allow decreasing the amount of necessary fresh water and nutrients for medium preparation for the microalgae culture considerably and would help to make the overall process more economic and sustainable (Rodolfi et al., 2003; Uduman et al., 2010). Typically, separation is performed by centrifugation after which the supernatant containing a variety of micronutrients, bacteria and algal debris, is disposed of in most cases. The use of MF and UF as polishing techniques to remove bacteria and algal debris can facilitate water recycling. The aim of the pilot test was to polish the supernatant produced with an automatic desludging disc centrifuge. The produced permeate was used for testing algae growth on recycled medium (data not shown). The tests were run for both the PVC-MF and the IPC-UF membrane. Fig. 6a shows the filtration results for the PVC-MF membrane immersed in supernatant first concentrated by a factor of 5 (VCF 5 ) and then kept constant through a feed and bleed operation. A severe loss in permeability was observed whenever the process temperature dropped below $8{ }^{\circ} \mathrm{C}$. This drop occurred twice during the pilot trials as indicated on Fig. 6 a. This phenomenon can be explained by the precipitation of one or more compounds when the solution reaches

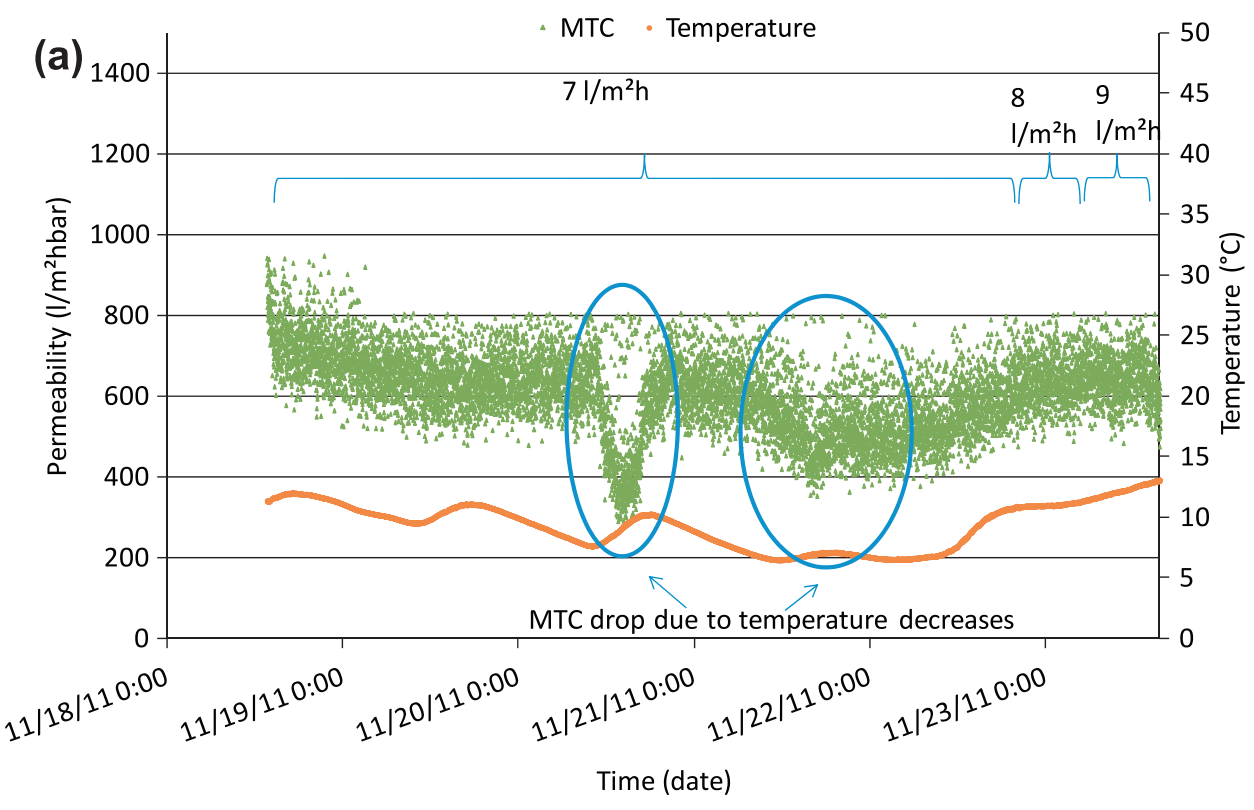

$\triangle \mathrm{MTC}$

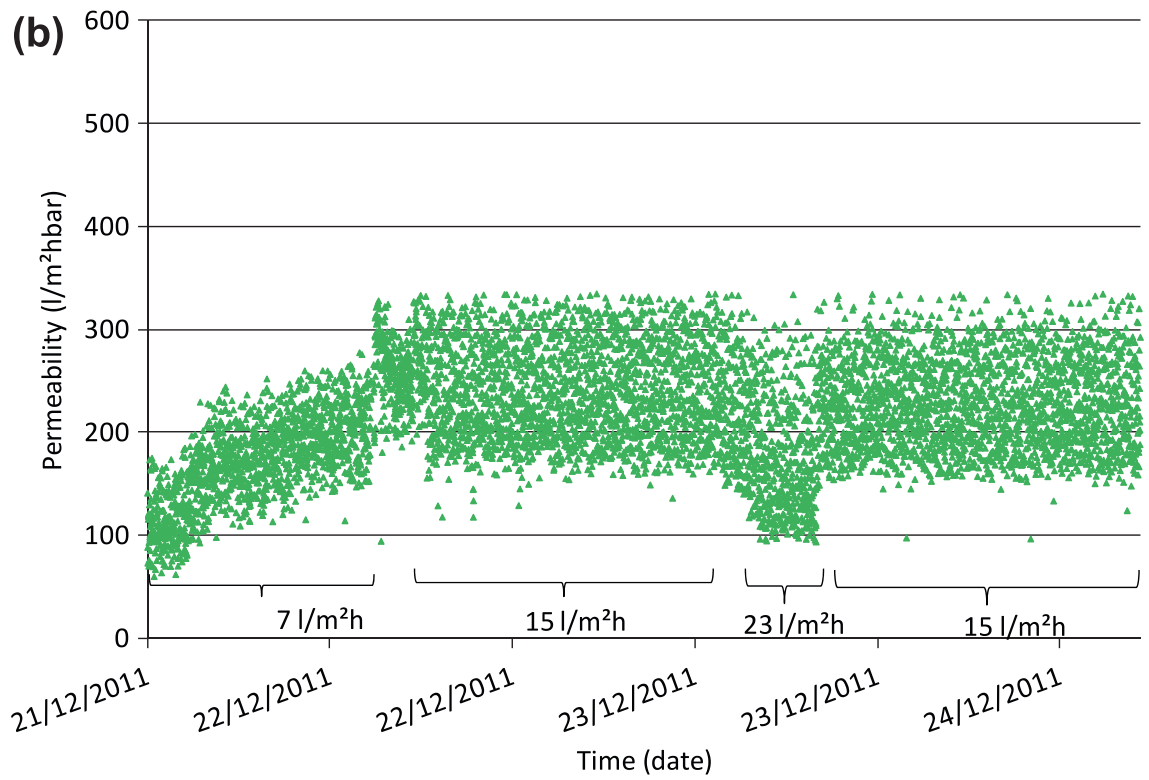

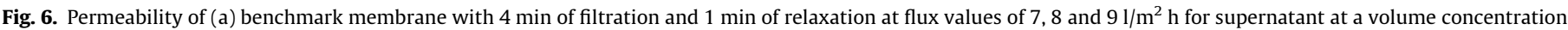

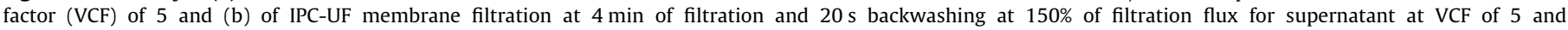
temperatures $>10^{\circ} \mathrm{C}$. Flux values varied from 7 and 15 to $23 \mathrm{l} / \mathrm{m}^{2} \mathrm{~h}$. 
Table 6

Energy consumption expressed per weight of algae input and per $\mathrm{m}^{3}$ of algae input $(2 \mathrm{~g} / \mathrm{l})$ of submerged membrane filtration with an IPC UF membrane for Nannochloropsis harvesting from an initial $2-10 \mathrm{~g} / \mathrm{l}$ at a fixed flux of $28 \mathrm{l} / \mathrm{m}^{2} \mathrm{~h}$, a PVC-MF membrane at a flux of $10 \mathrm{l} / \mathrm{m}^{2} \mathrm{~h}$, compared to only centrifugation up to $20 \% \mathrm{DCW}$ $(200 \mathrm{~g} / \mathrm{l})$.

\begin{tabular}{clll}
\hline Energy consumption & $\begin{array}{l}\text { Algae input } \\
\text { volumes }\left(\mathrm{m}^{3} / \mathrm{h}\right)\end{array}$ & $\begin{array}{l}\text { Concentration } \\
\text { traject }(\mathrm{g} / \mathrm{l})\end{array}$ & $\begin{array}{l}E_{\mathrm{W}}(\mathrm{kWh} / \mathrm{kg} \\
\mathrm{DCW})\end{array}$ \\
\hline $\begin{array}{c}\text { Scenario 1a (IPC-UF) } \\
\text { Membrane unit } \\
\text { (80\% recovery) }\end{array}$ & 100 & $2 \rightarrow 10$ & \\
$\quad \begin{array}{l}\text { Fluids pumping } \\
\text { Aeration }\end{array}$ & & & 0.006 \\
$\quad$ Centrifuge & 20 & $10 \rightarrow 200$ & 0.064 \\
Total (sum) & & & 0.100 \\
Scenario 1b (PVC-MF) & & & 0.169 \\
Membrane unit & 100 & $2 \rightarrow 10$ & \\
$\quad$ (80\% recovery) & & & 0.004 \\
$\quad \begin{array}{l}\text { Fluids pumping } \\
\text { Aeration }\end{array}$ & & & 0.180 \\
$\quad$ Centrifuge & 20 & $10 \rightarrow 200$ & 0.100 \\
$\quad$ Total (sum) & & & 0.284 \\
Scenario 2 & & $2 \rightarrow 200$ & 0.500 \\
$\quad$ Centrifuge & 100 & & \\
\hline
\end{tabular}

a temperature below $8{ }^{\circ} \mathrm{C}$. Later in this trial, when the flux was increased to 8 and $91 / \mathrm{m}^{2} \mathrm{~h}$, respectively, the temperature was fluctuating well above the limit of $8{ }^{\circ} \mathrm{C}$, so that losses in permeability were not caused by precipitation but by fouling effects. The benchmark membrane showed stable operation for flux values up to $8 \mathrm{l} /$ $\mathrm{m}^{2} \mathrm{~h}$; a further increase in flux caused a decrease in permeability. Filtration tests were repeated with the IPC-UF membrane with the same supernatant. First, the flux was fixed at $8 \mathrm{l} / \mathrm{m}^{2} \mathrm{~h}$ and the membrane was operated under identical conditions as the benchmark membrane: i.e. 4 min filtration - 1 min relaxation. The IPCUF membrane operated under these conditions showed a similar performance as the benchmark membrane (data not shown). The permeability values were not equal for both membranes as the benchmark membrane showed a permeability of about 500$600 \mathrm{l} / \mathrm{m}^{2} \mathrm{~h}$ bar whereas the IPC-UF membrane had a stable permeability of around $250 \mathrm{l} / \mathrm{m}^{2} \mathrm{~h}$ bar attributed to a difference in pore size and porosity. In a second period of the pilot trial, the effect of backwashing was evaluated. The IPC-UF membrane was switched without chemical cleaning to a filtration-backwashing regime at a reduced flux of $71 / \mathrm{m}^{2} \mathrm{~h}$. Fig. $6 \mathrm{~b}$ shows that the permeability recovered well after switching from relaxation to backwashing. During the stepwise flux increase up to $15 \mathrm{l} / \mathrm{h} \mathrm{m}^{2}$ the permeability increased even further. At $15 \mathrm{l} / \mathrm{h} \mathrm{m}^{2}$, a stable operation was achieved. A successive stepwise flux increase to $23 \mathrm{l} /$ $\mathrm{h} \mathrm{m}{ }^{2}$ showed a decrease in permeability. A 3.5-h run at $23 \mathrm{l} / \mathrm{h} \mathrm{m}^{2}$ showed no decrease in permeability. When the flux was restored at $15 \mathrm{l} / \mathrm{h} \mathrm{m}^{2}$ the permeability recovered to the original value which indicates that no irreversible fouling took place during filtration at $23 \mathrm{l} / \mathrm{h} \mathrm{m}^{2}$. It is noteworthy that, after incidents of heavy fouling, a longer backwashing period of 2 min allowed the membrane to recover its initial permeability without chemical cleaning (results not shown). The IPC membrane thus allows for a robust operation.

\subsection{Energy consumption}

Table 6 shows the estimation of the energy consumption expressed as $\mathrm{kWh} / \mathrm{kg}$ DCW when using IPC-UF or PVC-MF membranes in combination with centrifugation (scenarios $1 \mathrm{a}$ and $1 \mathrm{~b}$ ) and centrifugal harvesting alone (scenario 2 ) to a maximum concentration of $200 \mathrm{~g} / \mathrm{l}$. The calculations take into account a preconcentration step from an algae input concentration of $2 \mathrm{~g} / \mathrm{l}$ DCW to $10 \mathrm{~g} / \mathrm{l} \mathrm{DCW}$ via submerged membrane filtration and further con- centration through centrifugation from $10 \mathrm{~g} / \mathrm{l}$ to $200 \mathrm{~g} / \mathrm{l}$. The total energy consumption using membranes combined with centrifugation was low compared to typical energy consumption for algae harvesting via centrifugation (Borowitzka, 2005).

\section{Conclusions}

Lab tests show that critical flux is dependent on microalgae species and concentration, membrane material, pore size and operating conditions. The IPC membranes show improved flux and fouling resistance compared to the commercial benchmark MF membrane, primarily due to the use of backwashing. Compared to the benchmark membrane, the sustainable flux could be increased up to $300 \%$ for the IPC-UF. Calculations show that using membranes prior to centrifugation reduces the energy consumption of harvesting. As the results show PVDF to be a superior membrane material, VITO will develop a PVDF-IPC membrane to further improve the IPC membranes.

\section{Acknowledgements}

The authors wish to acknowledge MIP Vlaanderen for financial support to the ALCHEMIS project.

\section{References}

Arad, S., Friedlander, M., Ben Arie, R., Richmond, A., 1980. Alkalinity induced aggregation in Chlorella vulgaris. 1 . Changes in cell volume' and cell wall structure. Plant \& Cell Physiology 21, 27-35.

Babel, S., Takizawa, S., 2010. Microfiltration membrane fouling and cake behavior during algal filtration. Desalination 261, 46-51.

Bacchin, P., Aimar, P., Field, R.W., 2006. Critical and sustainable fluxes: theory experiments and applications. Journal of Membrane Science 281, 42-69.

Becker, E.W., 2007. Micro-algae as a source of protein. Biotechnology Advances 25, 207-210.

Bilad, M.R., Vandamme, D., Foubert, I., Muylaert, K., Vankelecom, I.F.J., 2012. Harvesting microalgal biomass using submerged microfiltration membranes. Bioresource Technology 111, 343-352.

Borowitzka, M., 2005. Culturing microalgae in outdoor ponds. In: Andersen, R.A. (Ed.), Algal Culturing Techniques. Elsevier Academic Press, San Diego, CA, pp. 205-217.

Doucha, J., Lívanský, K., 2008. Influence of processing parameters on disintegration of Chlorella cells in various types of homogenizers. Applied Microbiology Biotechnology 81, 431-440.

Doyen, W., Beckers, H., Adriansens, W., Dotremont, C., 2008. US Patent 20080164208A1.

Dragone, G., Fernandes, B., Vincente, A.A., Teixeira, J.A., 2010. Third generation biofuels From microalgae, [webpage] <http://www.formatex.info microbiology2/1355-1366.pdf>, [consulted 28.09.11].

Greenwell, H.C., Laurens, L.M.L., Shields, R.J., Lovitt, R.W., Flynn, K.J., 2010. Placing microalgae on the biofuels priority list: a review of the technological challenges. Jornal of Royal Society Interface 7, 703-726.

Grima, E.M., Belarbi, E.-H., Acién Fernández, F.G., Medina, A.R., Chisti, Y., 2003. Recovery of microalgal biomass and metabolites: process options and economics. Biotechnology Advances 20, 491-515.

Ladner, D.A., Vardinaad, D.R., Clark, M.M., 2010. Effects of shear on microfiltration and ultrafiltration fouling by marine bloom-forming algae. Journal of membrane Science 356, 33-43.

Lewin, J.C., Lewin, R.A., Philpotdt, E., 1958. Observations on Phaeodactylum tricornutum. Journal of General Microbiology 18, 418-426.

Mata, T.M., Martins, A.A., Caetano, N.S., 2010. Microalgae for biodiesel production and other applications: a review. Renewable and Sustainable Energy Reviews 14, 217-232.

Petrusevski, B., Bolier, G., Van Breemen, A.N., Alaerts, G.J., 1995. Tangential flow filtration: a method to concentrate freshwater algae. Water Research 29, 14191424.

Pittman, J.K., Dean, A.P., Osundeko, O., 2010. The Potential of Sustainable Algal Biofuel Production Using Wastewater Resources, [webpage] <http:// helhaphl2010-02.wikispaces.com/file/view/sdarticle2.pdf>, [consulted 09.11.11].

Rodolfi, L., Graziella, C.Z., Barsanti, L., Rosati, G., Trdici, M.R., 2003. Growth medium recycling in Nannochloropsis sp. mass cultivation. Biomolecular Engineering 20 243-248.

Rossignol, N., Vandanjon, L., Jaouen, O., Quemeneur, F., 1999. Membrane technology for the continuous separation microalgae/culture medium: compared performances of cross flow microfiltration and ultrafiltration. Aquacultural Engineering 20, 191-208.

Singh, J., Gu, S., 2010. Commercialization potential of microalgae for biofuels production. Renewable and Sustainable Energy Reviews 14, 2596-2610. 
Spolaore, P., Joannis-Cassan, C., Duran, E., Isambert, A., 2006. Commercia applications of microalgae. Journal of Bioscience and Bioengineering 101 (2), 87-96.

Uduman, N., Qi, Y., Danquah, M.K., Forde, G.M., Hoadley, A., 2010. Dewatering of microalgal cultures: a major bottleneck to algae-based fuels. Journal of Renewable and Sustainable Energy 2, 012701.

Wolkers, H., Barbosa, M., Kleinegris, D., Bosma, R., Wijffels, R.H., 2011. Microalgae: the green gold of the future?, Large-scale sustainable cultivation of microalgae for the production of bulk commodities, Wageningen UR, [Webpage] [Consulted 12/10/2011].

Xing, C., Wang, J., 2008. Overview of MBR on research and application in China. In: The 3rd WEPA International Forum on Water Environmental Governance in Asia, proceedings.
Yang, J., Xu, M., Zhang, X., Hu, Q., Sommerfeld, M., Chen, Y., 2011. Life-cycle analysis on biodiesel production from microalgae: water footprint and nutrients balance. Bioresource Technology 102, 159-165.

Zhang, G., Ji, S., Gao, X., Liu, Z., 2008. Adsorptive fouling of extracellular polymeric substances with polymeric ultrafiltration membranes. Journal of Membrane Science 309, 28-35.

\section{Further reading}

Gonzalez, A., Kafarov, V., 2010. Design of a multifunctional reactor for third generation biofuels production. Chemical Engineering Transactions 21, 12971302. 